\title{
PLURALIDAD DE JURISDICCIONES Y TUTELA DE DERECHOS: LOS EFECTOS DE LA INTEGRACIÓN EUROPEA SOBRE LA RELACIÓN ENTRE EL JUEZ ORDINARIO Y EL TRIBUNAL CONSTITUCIONAL* Jurisdictional Diversity and Constitutional Rights Adjudication: The Effects of European Integration on the Relationship between National Judiciary and the Constitutional Court \\ MIRYAM RODRÍGUEZ-IZQUIERDO SERRANO \\ Universidad de Sevilla
}

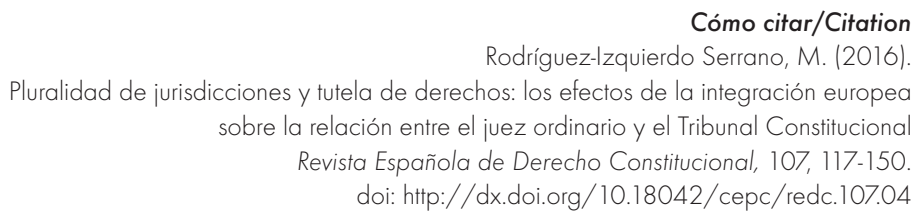

Resumen

Nuestro sistema constitucional de protección de derechos fundamentales y el sistema de aplicación jurisdiccional del derecho de la Unión Europea (UE), incluida

* El presente trabajo es fruto del estudio realizado con ocasión de una estancia de investigación en el gabinete del abogado general Cruz Villalón, en el Tribunal de Justicia de la Unión Europea, durante la primavera de 2015. La estancia fue cofinanciada por el proyecto "Construyendo un estándar europeo de protección de los derechos fundamentales: de la Carta de Derechos Fundamentales de la Unión a las Constituciones, pasando por el CEDH» (DER2013-41303-P) —Ministerio de Economía y Competitividad, Gobierno de España-y por el V Plan Propio de Investigación de la Universidad de Sevilla. Todas las traducciones al español de textos citados, con originales en otros idiomas, han sido realizadas por la autora. 
la Carta de Derechos, tienen un vértice en común: los jueces y tribunales de la jurisdicción ordinaria. En ambos sistemas, el Tribunal Constitucional (TC) y el Tribunal de Justicia de la Unión Europea (TJUE) cumplen una función de garantía objetiva de los derechos fundamentales de cada una de sus normas básicas. Pero también esos tribunales, el TC y el TJUE, participan de los procesos de garantía de derechos que se sustancian ante los tribunales ordinarios. Las interferencias son inevitables. Este artículo se propone analizar qué ocurre y cómo se alteran esos sistemas de garantía cuando los respectivos procedimientos de tutela se cruzan.

\section{Palabras clave}

Justicia constitucional; Tribunal Constitucional; Tribunal de Justicia de la Unión Europea; poder judicial; derechos fundamentales; Carta de Derechos de la Unión Europea; tutela judicial efectiva; cuestión prejudicial.

\section{Abstract}

Spanish constitutional system for the protection of constitutional rights and European Union system for the judicial enforcement of EU law, including the Charter, have one thing in commom: national ordinary courts. In both systems, the Constitutional Court and the Court of Justice are also especial and supreme guarantors of the fundamental rights, as proclaimed either in the Constitution or in the Charter. Crossroads and intersections in procedures are unavoidable. This article analyses what happens and how those systems of enforcement are altered whenever they meet.

\section{Key words}

Constitutional adjudication; Spanish Constitutional Court; Court of Justice of the European Union; judicial power; constitutional rights; Charter of Fundamental Rights of the European Union; effective judicial protection; preliminary reference. 


\section{SUMARIO}

I. INTRODUCCIÓN. II. PLURALIDAD DE JURISDICCIONES Y TUTELA DE DERECHOS. III. EL TC ANTE EL DERECHO DE LA UE Y LA EXCEPCIÓN DE LOS DERECHOS: 1. La excepción de los derechos. 2. Inflexiones e inflexibilidades. 3. La doble visión del TC. IV. LOS DERECHOS FUNDAMENTALES DE LA UE Y LA JURISDICCIÓN ORDINARIA: PEQUEÑO REPERTORIO: 1. Tutela judicial efectiva. 2. Igualdad y no discriminación. 3. Protección de datos. V. CONCLUSIONES: BAJO LA VISIÓN SUPRANACIONAL Y DESDE LA VISIÓN DEL JUEZ ORDINARIO. BIBLIOGRAFIA.

\section{INTRODUCCIÓN}

El derecho de la UE no tiene relevancia constitucional. Esta afirmación, que el TC español no se ha cansado de repetir desde su temprana jurisprudencia en la materia, y que conecta con la comprensión que él mismo tiene de su función de garante de la norma suprema (Cruz Villalón, 2004: 67)1, es la clave inicial de las reflexiones que voy a plantear. Relevancia constitucional, dimensión constitucional, naturaleza constitucional, trascendencia constitucional... En un primer momento, el sustantivo usado puede ser lo de menos, pues lo de más es esa insistencia en la descalificación: irrelevante. A la connotación negativa se superponen, en un segundo momento, ciertas ambigüedades que la doctrina ha puesto de relieve de forma reiterada y que, en la medida en que siguen reproduciéndose en la jurisprudencia constitucional sobre el derecho de la UE, se nos aparecerán a lo largo de este trabajo, y de manera natural, en cuanto sean invocadas ${ }^{2}$.

1 Los Tribunales Constitucionales nacionales asumen, con matices, las dinámicas de la integración, pero no pueden dejar de lado su propia identidad como jueces, que reside en la Constitución nacional y en su función básica, que es el control de la constitucionalidad doméstica (Cruz Villalón, 2004: 67 y 68).

2 Sin posibilidad de ofrecer una relación exhaustiva de los autores que han escrito sobre esta cuestión, me permito destacar los siguientes trabajos: Díez Picazo (1998: 255); Pérez Tremps (1994: 165); López Castillo (1996: 495 y ss.); López Castillo (1998: 213), y Vírgala Foruria (2002: 202). 
Pues bien, esos dos aspectos de la relación del TC con el derecho europeo, ambigüedades en la argumentación e insistencia en la atonía constitucional, tan pronto pueden estar disimulando dudas secretas del juez constitucional como mostrando la simple confirmación de algo innegable y cierto. $Y$ es que ni los tratados europeos ni el derecho derivado son Constitución, así que, en consecuencia, no tienen ni rango ni fuerza de tal. Del significado de estos dos sustantivos, rango y fuerza constitucional, se desprende algo más específico que lo que se deduce de las ideas de trascendencia o relevancia, pues mientras aquellos se refieren a la dimensión de lo constitucional-formal, estas parecen negar cualquier dimensión constitucional sustantiva a los conflictos que se producen en la aplicación del derecho de la UE y que, por una razón u otra, acaban siendo dirimidos ante el $\mathrm{TC}^{3}$. Aceptando estas premisas, apenas haré apuntes en relación con la dimensión constitucional-formal, pues ese no es el objeto de estas reflexiones. Al contrario, en las páginas que siguen pretendo partir de esa realidad formal para indagar los efectos que la postura adoptada por el TC, con sus ambigüedades, tiene sobre la tutela que de los derechos fundamentales deben llevar a cabo los jueces y tribunales y en la que, desde 2009, la aplicación jurisdiccional de la Carta de Derechos introduce una nueva dificultad.

Como es sabido, es en los derechos fundamentales donde la postura del juez constitucional cede y donde las aludidas ambigüedades florecen. Por eso la vigencia de la Carta refuerza hoy en día los problemas del relativo ostracismo del TC ante el derecho de la UE. Si bien es cierto que ni los tratados ni el derecho derivado son Constitución, por carecer de rango de tal, no lo es menos que la aplicación de una declaración supranacional de derechos fundamentales, como la Carta, tiene relevancia, naturaleza y trascendencia constitucional. Eso, sin embargo, es algo que el TC en ningún momento niega en lo que a su dimensión material se refiere, reconociendo a la Carta la misma posición y función interpretativa que tiene el Convenio a través del art. 10.2 CE, esto es, la de servir de guía hermenéutica cuando en un conflicto de derechos

3 Desde su temprana jurisprudencia en la materia, el TC ha hablado en distinto sentido de «rango y fuerza» y de «relevancia» constitucional del derecho europeo. Vid. la primera sentencia sobre estos asuntos, la STC 28/1991: el fundamento jurídico 4 explica que el mandato del art. $93 \mathrm{CE}$ no confiere rango constitucional al derecho europeo y, más tarde, el 5 habla de irrelevancia constitucional al declarar que el posible conflicto normativo entre el art. 211.2.d) LOREG y el 5 del Acta Electoral Europea no atentaba contra ningún precepto constitucional (Azpitarte Sánchez, 2002: 123, nota 33). Con motivo de aquella sentencia, críticamente también en relación con la idea de infraconstitucionalidad del derecho europeo, vid. Mangas Martín (1991: 587). 
fundamentales se halle envuelto el derecho de la $\mathrm{UE}^{4}$. Sin embargo, para los jueces y tribunales ordinarios, según les ha indicado el propio juez constitucional, la Carta tiene una posición específica en el sistema de fuentes y su carácter es imperativo; es una norma aplicable como cualquier otra norma de derecho europeo.

La comprensión desintegrada de un mismo texto normativo, la Carta, en su recepción por parte del ordenamiento jurídico interno responde a razones formales, pero también tiene una serie de consecuencias sustantivas. Debido a ello, y a causa de la diversa relación de las dos jurisdicciones estatales, la ordinaria y la constitucional, con la funciones tutelares del TJUE, hay un reajuste del originario sistema constitucional de garantía jurisdiccional de derechos fundamentales. Al sistema basado en la tutela judicial efectiva del $24 \mathrm{CE}$ y en los recursos de amparo judicial y constitucional del 53.2 CE, se une el aportado por la arquitectura jurisdiccional de los tratados, en el que entran en juego tanto el TJUE como, de nuevo, la justicia ordinaria. En ese desajuste entre el plano de lo constitucional-material y el de lo constitucional-formal, asumo como punto de partida que el plano formal, en lo que al derecho de la UE se refiere, se ajusta a los parámetros marcados por la jurisprudencia del TC, pero que no ocurre lo mismo con el plano material ${ }^{5}$. Es decir, el derecho de la UE no tiene ni rango ni fuerza constitucional, pero sí llega a poseer una relevancia constitucional en conflictos específicos.

$\mathrm{Y}$ al fin, sentadas las premisas iniciales, expongo mi propósito, que es dedicar la primera parte de este trabajo a repasar algunas cuestiones clave de la relación entre las jurisdicciones estatales en materia de tutela de derechos, para elaborar un mapa de la incidencia de tales relaciones sobre la aplicación interna del derecho de la UE [1]. En segundo lugar destacaré los aspectos más sobresalientes de la jurisprudencia del TC en torno a la relación entre derechos

4 En realidad el TC utilizó desde muy pronto una interpretación extensiva del 10.2 CE que le permitía aplicar las regulaciones comunitarias con incidencia iusfundamental en procesos de amparo constitucional (Saiz Arnaiz, 1999: 172 y ss.). De hecho, dio el mismo tratamiento a la Carta incluso antes de su entrada en vigor (Sánchez Legido, 2004: 401).

5 Y esto en realidad no ocurre solo con los derechos fundamentales, sino también con las contradicciones entre las normas europeas y nacionales y la función del principio de primacía. Requejo Pagés, al tratar sobre la cuestión de la irrelevancia, da por sentado que con ella el TC se refiere al hecho de que la validez de las normas nacionales no pueda ser discutida sobre la base del derecho de la UE: «resulta discutible la afirmación de que, por afectar a su aplicabilidad y no a su validez, la compatibilidad de una norma interna con el derecho de la UE es un asunto que carece de toda dimensión constitucional»(Requejo Pagés, 2015: 494). 
fundamentales y derecho europeo [2] y en tercer término señalaré algunos casos en los que la jurisdicción ordinaria se ha apoyado en el TJUE para otorgar a los contenidos sustantivos de los derechos fundamentales un enfoque que el TC no había podido darles [3]. Por último, unas breves conclusiones me ayudarán a reflexionar sobre los efectos secundarios de la posición del TC, ello al hilo de la doctrina del TJUE en materia de aplicación de la Carta por los Estados miembros [4].

\section{PLURALIDAD DE JURISDICCIONES Y TUTELA DE DERECHOS}

Si la primera clave de estas reflexiones es la espinosa irrelevancia constitucional del derecho de la UE, la segunda está en la naturaleza de Estado constitucional integrado que adquiere el Estado español por su adhesión al sistema supranacional de la $\mathrm{UE}^{6}$. Como consecuencia de tal integración, existe una pluralidad de jurisdicciones competentes para la tutela de los derechos fundamentales. Las representaremos gráficamente sobre la base de un triángulo invertido. En el vértice inferior, a los jueces ordinarios se los considera los garantes naturales de la tutela subjetiva de los derechos fundamentales y los aplicadores primarios del derecho de la UE, incluida la $\mathrm{Carta}^{7}$. Por su parte, en los vértices superiores el juez constitucional y el juez europeo son los supremos intérpretes del Título I de la Constitución y de la Carta de Derechos, respectivamente, así como los custodios de la garantía objetiva de sendas declaraciones iusfundamentales. En un principio, y con la omisión quizás imperdonable, pero consciente, del juez del Convenio, la pluralidad de jurisdicciones en materia de garantía de derechos podría presentarse según el siguiente diagrama ${ }^{8}$ :

6 Por todos, acudimos a Rubio Llorente cuando consideraba la transformación a la que se somete el Estado a causa de su integración en la UE como un proceso auténticamente estructural, al cual el constitucionalismo estatal aún se ha adaptado de manera deficiente (Rubio Llorente, 1996: 9-33).

7 Se habla de la «doble alma iusfundamental» del juez ordinario en Ugartemendia Eceizabarrena (2013: 395).

8 Sobre la posición central del juez ordinario en esta materia, incluyendo en el diagrama de relaciones al Tribunal Europeo de Derechos Humanos como juez del Convenio, vid. Alonso García (2014). 


\section{Diagrama 1: Jurisdicciones y Tutela de Derechos Fundamentales}

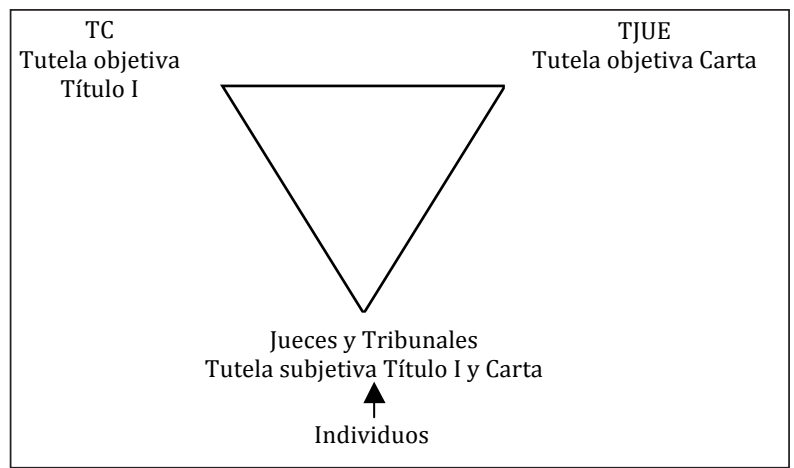

Destacando, de entrada, la posición de garantes objetivos que tienen el TC y el TJUE, no olvidamos que, al servicio de ella', el recurso de amparo también otorga al juez constitucional la función de tutela subjetiva directa de ciertos derechos constitucionales y que esa tutela requiere, por lo general, la previa actuación de los jueces y tribunales ordinarios. La cuestión prejudicial también puede llevar a una acción de tutela mediata de derechos por parte del TC. Con importantes matices, el TJUE asume la garantía subjetiva de los derechos en la medida en que pueda derivarse una práctica de tutela individual cuando los particulares tienen acceso al recurso de anulación ante el Tribunal General, con posible casación ante el TJUE. La cuestión prejudicial, indirecta y puntualmente, también puede convertirse de facto en garantía individual de los derechos, si bien la realidad es que será el juez estatal, el que haya elevado la cuestión, el que lleve a cabo la tutela última de los derechos individuales invocados. La inexistencia de un amparo específico ante el TJUE, uno para la tutela de los derechos de la Carta, hace inverosímil equiparar las funciones tutelares subjetivas del TC y del TJUE. En resumen, no hay que perder de vista que nos hallamos ante una pluralidad de jurisdicciones tutelares de derechos fundamentales individuales, conformada por un juez ordinario, constitucional y europeo, en el seno de la cual dos de ellas se erigen como garantes supremas de la protección objetiva de las declaraciones iusfundamentales de referencia, Título I y Carta. La corrección al diagrama inicial daría

9 El recurso de amparo sirve a la unidad interpretativa, aunque esta no sea su única función (Pérez Tremps, 1985: 232). En efecto, la condición de proceso al servicio de la interpretación de la Constitución que tiene el amparo constitucional no hace que desaparezca ni se diluya «la función de tutela» individual que dispensa. Así lo explica recientemente Álvarez-Ossorio Micheo (2015: 131). 
como resultado el que presento a continuación, obviando, por ahora, la relación entre TC y TJUE a través de la cuestión prejudicial:

\section{Diagrama 2: Jurisdicciones y Tutela de Derechos Fundamentales}

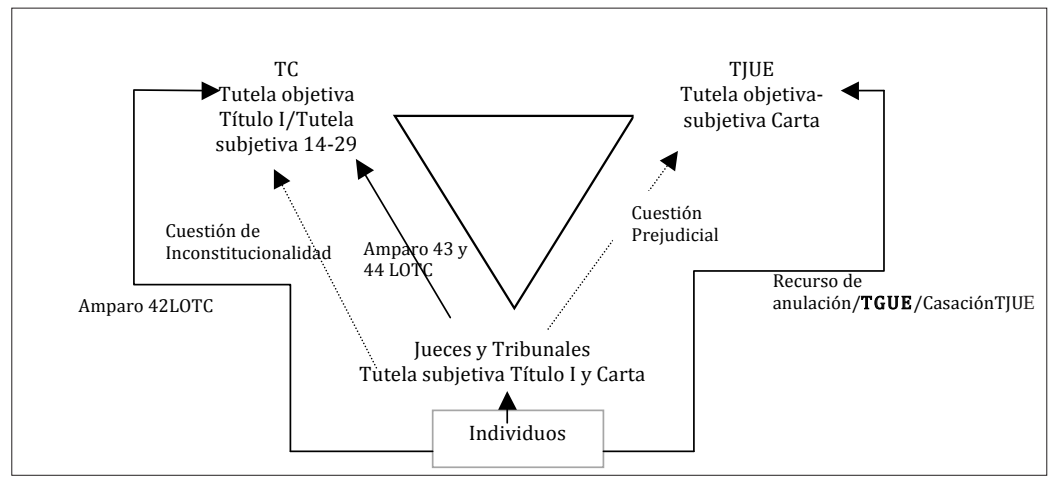

Según todo esto, puede sostenerse que hay un sistema de protección subjetiva de derechos fundamentales que hace converger en los jueces y tribunales ordinarios tanto la tutela natural de los derechos constitucionales como la de los derechos europeos. Los jueces son los garantes oficiales de los derechos individuales del Título I, según el juego de los 24.1 y 53.2 de la Constitución, y también los aplicadores corrientes del derecho de la UE, incluida la Carta de Derechos (Ugartemendia Eceizabarrena, 2013: 396 y 397). Esto último es algo que ya se había afirmado con los derechos fundamentales de la UE cuando funcionaban en su originaria dimensión de principios generales y elementos comunes de las tradiciones constitucionales de los Estados miembros y además son varios los elementos que apuntan al juez estatal como aplicador básico de la Carta: en primer lugar, el diseño de la propia jurisdicción de la UE, que se apoya en la estructura orgánica e institucional de las jurisdicciones estatales para hacer efectivo su Derecho; en segundo lugar, la estructura de su sistema de recursos, que comprende de manera restrictiva la legitimación individual de los ciudadanos europeos para acudir al TJUE; en tercer lugar, la conexión de los elementos anteriores con el principio-derecho a la tutela judicial efectiva, y de nuevo con el art. 24 de la Constitución, que residencia en el juez estatal la función de dar efectividad al derecho de la UE en la medida en que este otorgue intereses subjetivos y derechos a los individuos (Azpitarte Sánchez, 2002: 109) ${ }^{10}$.

10 Sobre el art. 24 CE como cláusula constitucional de integración supranacional: Ugartemendia Eceizabarrena (2013: 425). 
Dentro de tal configuración, plural, del marco jurisdiccional de protección de los derechos fundamentales, los jueces y tribunales españoles se encuentran con dos parámetros de constitucionalidad material a la hora de evaluar los conflictos que surjan en torno a esto: la Constitución y la Carta. Y, como es evidente, también se encuentran con dos intérpretes superiores, y supremos, de referencia. En el desempeño de sus funciones, los jueces estatales han de mirar al juez constitucional y al juez europeo, a los dos, ya que las decisiones y la doctrina jurisprudencial de uno y de otro son de obligado seguimiento, si bien en cada caso de diferente forma. En el caso del TC, la obligación nace de la propia lógica imperativa de la supremacía constitucional, de la superioridad de la jurisdicción constitucional sobre la ordinaria en materia de garantías constitucionales, dispuesta en el art. 123.1 CE, de la dicción del art. 5.1 de la LOPJ y de la función revisora, y casi casacional, del recurso de amparo cuando sujeta las decisiones de los jueces ordinarios en materia de derechos a la verificación del juez constitucional (Pérez Tremps, 1985: 223). En el caso del TJUE, la obligatoriedad de sus decisiones para la jurisdicción ordinaria deriva de la atribución de competencias que resulta del art. $93 \mathrm{CE}$, el cual, e incluso desde la perspectiva del $\mathrm{TC}^{11}$, por una parte otorga a la jurisprudencia de Luxemburgo una posición preeminente en el sistema estatal de fuentes, pues lo hace cuando se trata de aplicar el derecho de la UE, mientras que, por otra parte, erige al europeo en juez natural y predeterminado por la ley, lo que hace necesaria la cuestión prejudicial en caso de duda sobre su interpretación o validez en sede jurisdiccional ordinaria.

De manera esquemática, y tal como se representa en el segundo diagrama, esa es la situación funcional de la jurisdicción ordinaria en relación con los derechos fundamentales, en su doble dimensión estatal y supranacional. Pero de cara a las reflexiones que quiero hacer, aludiré a otro elemento: el de la posición institucional de jueces y tribunales estatales en sus relaciones con las jurisdicciones constitucional y europea. Considero que revisar esa posición es de interés en la medida en que esta influye en la manera en la que los jueces españoles se relacionan con los derechos de la Constitución y con los de la Carta.

11 El mismo TC confirma esa obligatoriedad, en especial, en su STC 145/2012. El TC sostiene que si el juez ordinario deja de tener en cuenta una resolución del TJUE que sea determinante para el proceso, porque lo sea para la interpretación y aplicación interna del derecho de la UE, se vulnera el derecho del art. 24.1 CE, tutela judicial efectiva, en su dimensión de «derecho a recibir una sentencia motivada y fundada en Derecho», en concreto por resultar irracional y arbitraria la selección de la norma aplicable en el proceso. 
Volviendo al diagrama, en el lado izquierdo del triángulo estaría el TC que, como en todos los sistemas que responden al modelo del «sistema europeo de control de constitucionalidad", introduce ya de por sí una pluralidad jurisdiccional en el orden interno. Los tribunales constitucionales se conciben como órganos sobrepuestos a la función del poder neutro de los jueces, separados del poder judicial, y a los que se reserva la defensa objetiva de la Constitución ${ }^{12}$ a través de diferentes técnicas. Son órganos interpuestos, artificiales, que no son producto de la lógica jurídica aparejada a la fuerza normativa de la Constitución, sino de una ingeniería constitucional que nace de la preferencia inicial del constitucionalismo europeo por la garantía política de la constitución y de su reticencia, heredada, a dejar la defensa general de la ley fundamental, y de los derechos constitucionales en particular, en manos de los jue$\operatorname{ces}^{13}$. Ahora bien, la justicia constitucional concentrada no exime a la jurisdicción ordinaria de la tarea de aplicación jurisdiccional de la Constitución, y en consecuencia de la de los derechos fundamentales, pues esta va indisolublemente unida a la aplicación jurisdiccional del ordenamiento, pero sí que la pone en concurrencia con el ejercicio de la misma función por otra jurisdicción, la constitucional, que surge de ese recelo histórico-político ante ella y cuya competencia, superpuesta, es suprema, exclusiva y especial. Se produce así una tensión entre ambos órdenes jurisdiccionales, y de esa tensión surge la cuestión de los límites de la competencia del TC en la revisión de los actos del poder judicial. Sin duda, es una cuestión difícil de resolver, más cuando se evidencia que la interpretación constitucional ha de efectuarse en gran parte sobre la base de normas y disposiciones de rango infraconstitucional.

En el otro lado del triángulo, las relaciones entre los jueces y tribunales ordinarios y el TJUE no reflejan ninguna tensión similar a la conocida entre estos y TC. En primer lugar porque la reticencia hacia los jueces ordinarios funcionó en sentido inverso en el diseño de la jurisdicción europea, que convirtió a los jueces nacionales en jueces comunitarios. En segundo lugar, porque las doctrinas del efecto directo y de la primacía del derecho de la UE les trasladó la responsabilidad parcial de dar garantía objetiva al derecho de la UE, así como la facultad de determinar el derecho aplicable con preferen-

12 Por más que esa defensa objetiva en los casos concretos y particulares supere el marco objetivo para convertirse en «exigencia de todo sujeto público o privado en sus relaciones jurídicas» (Pérez Tremps, 1985: 9).

13 Tendencia que, es sabido, se altera cuando los Estados europeos asumen elementos federales en su organización constitucional, tal como se explica en Cruz Villalón (1987: 27 y ss.). 
cia, aun con el posible desplazamiento de la legislación estatal. En tercer lugar, el juez nacional recibió el privilegio de estar en comunicación directa con un tribunal supranacional, a través de la cuestión prejudicial, un tribunal que estaba por encima de ellos, pero con el que no tenían orgánicamente ninguna subordinación o vinculación jerárquica. Y en cuarto lugar, de nuevo, porque la cuestión prejudicial, a diferencia del amparo constitucional, no conllevaba el riesgo de reproche al juez nacional por su actuación ${ }^{14}$.

Por último, en el lado superior del triángulo se sitúa la relación entre la jurisdicción constitucional y la europea. En otros Estados miembros, y sobre todo si nos referimos a los tribunales constitucionales alemán e italiano, dicha relación se ha venido articulando de forma extraoficial a través del denominado diálogo judicial, pero lo cierto es que la cuestión prejudicial es, de suyo, la vía oficial. Por tanto, la comprensión formal de la relación de los órganos jurisdiccionales con funciones constitucionales y el TJUE respondería a un diagrama idéntico al anterior, en el que simplemente habría que incluir la conexión habilitada a través de la cuestión prejudicial. La función del procedimiento prejudicial en tal relación tendría que ser la garantía objetiva, con incidencia subjetiva, de los derechos de la Carta. Es decir, por más que el proceso de referencia ante el TC, un recurso de amparo o una cuestión de inconstitucionalidad, tuviese como objeto los derechos del Título de I de la Constitución, el TJUE siempre resolvería sobre la interpretación de los derechos europeos. Así, la cuestión prejudicial se activaría en el siguiente escenario: cuando en un conflicto se viera envuelto el derecho de la UE y coincidieran contenidos iusfundamentales del Título I y derechos fundamentales europeos. Su finalidad sería asegurar la armonización o conformidad entre contenidos iusfundamentales constitucionales y supranacionales.

Y digo que «se activaría», manteniendo el condicional, porque lo cierto es que las reticencias de los tribunales constitucionales a utilizar la cuestión prejudicial son muchas. Van venciéndose, sí. En España ya existió Melloni y

14 Karen Alter explica cómo los tribunales estatales se aprovechan de la posición que les da el derecho comunitario, a través de la cuestión prejudicial, para burlar obstáculos impuestos por las leyes y por los propios sistemas jurisdiccionales estatales (Alter, 2001: 33 y ss.). Stone Sweet destaca el hecho de que fueron intereses privados los que activaron el proceso de integración a través de la cuestión prejudicial (2000: 165). Sobre la ampliación del conjunto de actores interesados en la efectividad del derecho comunitario a través de la judicatura nacional y lo que ello significa de superación del paradigma iusinternacional clásico vid. Weiler (1995: 136 y ss.). 
en Alemania tuvieron Gauweiler ${ }^{15}$, pero no hay que perder de vista que la del TC y la del TJUE son dos jurisdicciones materialmente constitucionales cuya relación no es jerárquica, sino cooperativa, pero que sobre todo resulta ser competitiva. No es jerárquica, en ningún sentido, como no es jerárquica la relación entre los sistemas normativos de referencia, el supranacional y el constitucional ${ }^{16}$, y como sí lo es la de la jurisdicción ordinaria con ambas; si bien en este último caso la jerarquía opera en sentido diverso. Para el TJUE el TC es un órgano jurisdiccional a efectos de la cuestión prejudicial. Para el TC, el TJUE es un juez competente en la interpretación del derecho de la UE y ese derecho se excluye de su propio ámbito de competencia, a excepción o con el matiz de lo que ocurre con los derechos fundamentales.

\section{Diagrama 3: Jurisdicciones y Tutela de Derechos Fundamentales}

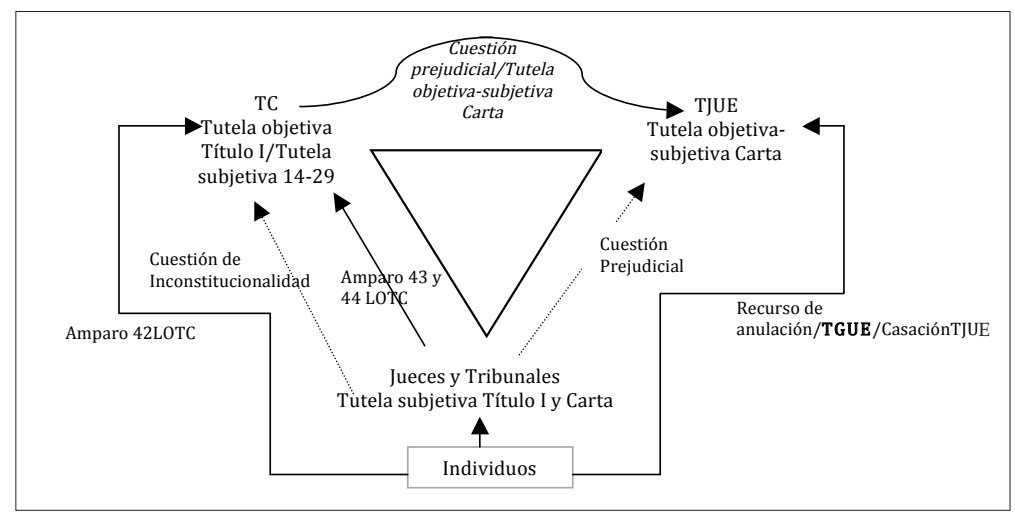

Ante el tercer diagrama, un observador lego podría pensar que las relaciones entre jurisdicciones en materia de garantía de derechos fundamentales están perfectamente ordenadas. Sin embargo, la realidad es otra bien distinta. Existe un cortocircuito originado por la diferente naturaleza de las jurisdiccio-

15 Sobre Gauweiler en particular, y la remisión de cuestiones prejudiciales por los órganos jurisdiccionales con funciones constitucionales, en general, me permito remitir al específico trabajo de Lohse (2015: 1491 y ss.) dentro del monográfico de Dicosola, Fasone y Spigno (eds.) (2015: 1317 y ss.).

16 Entran aquí las reflexiones sobre el pluralismo o pluralidad constitucional en el espacio europeo, cuyas relaciones se han definido, entre otras formas, como modos de interacción y de metaconstitucionalidad (Cruz Villalón, 2004: 139). Vid., también, Walker (2002: 354 y ss.). Una concepción distinta de la interrelación no jerárquica entre complejos normativos se encuentra en MacCormic (1999: 104). 
nes ordinaria y constitucional, cortocircuito que se ve agravado por los distintos modos de relación que ambas entablan tanto con el TJUE, y la cuestión prejudicial como procedimiento, como con la propia jurisprudencia del Tribunal de Justicia como un elemento de resolución de conflictos. El cortocircuito, como trataré de explicar en los dos epígrafes siguientes, es patente y más aún tras la primera cuestión prejudicial del TC. Veamos cómo se concretan esas alteraciones y cómo pueden influir en la aplicación de la Carta de Derechos.

\section{EL TC ANTE EL DERECHO DE LA UE Y LA EXCEPCIÓN DE LOS DERECHOS}

Como se ha anticipado, el TC español no considera que el derecho de la UE sea una cuestión constitucional. Las excepciones a esta apreciación básica son contadas y se refieren a modos de conflicto concretos. En primer lugar, y de manera lógica, una excepción es el control de constitucionalidad previo del derecho primario a través del mecanismo del art. $95 \mathrm{CE}$. La segunda excepción, que responde a una lógica distinta, son los derechos fundamentales; y la tercera, los conflictos en los que el desarrollo del derecho de la UE incide sobre la distribución de competencias interna entre el Estado y las comunidades autónomas.

Respecto a la referida postura general del TC, hay que insistir en que no es fruto de la simple tozudez, sino una consecuencia lógica de su posición en el sistema constitucional español, además de un efecto natural de la articulación de las relaciones entre el derecho estatal y el de la UE, basadas en el principio de atribución. Repitiendo la secuencia lógica del asunto: el TC no es un órgano del poder judicial, su función no es la aplicación o la interpretación de la legalidad ordinaria, sino de la Constitución, y el derecho de la UE, en el momento de su aplicación y en los ámbitos de competencia atribuida a la misma, plantea cuestiones de legalidad ordinaria y no de Constitución (Rodríguez Iglesias y del Valle Gálvez, 1997: 354).

En lo que aquí interesa, tanto el argumento general de la irrelevancia constitucional del derecho europeo como la excepción de los derechos fundamentales quedaron sentados en la doctrina del TC desde el principio, en la STC $28 / 1991^{17}$. Pero, quizás porque el derecho de la UE es, con matices cada

17 Una Decisión del Consejo, relativa a la elección de los miembros del Parlamento Europeo, sembraba la duda acerca de la compatibilidad entre la condición de parlamentario europeo y la de miembro del parlamento vasco. Para el Parlamento del País Vasco, el asunto requería una consulta al TJUE. Para el TC, en todo caso, habría de 
vez más significativos, fundamentalmente económico, la ocasión para que la excepción estrella ${ }^{18}$ cobrase protagonismo en una resolución del TC se hizo esperar. Por motivos discursivos, y en atención a los límites de extensión de este trabajo, me ceñiré a una breve retrospectiva y tan solo incluiré una pequeña selección de resoluciones sobre la materia.

\section{LA EXCEPCIÓN DE LOS DERECHOS}

Los derechos fundamentales actuaron en la UE, hasta la entrada en vigor de la Carta, como principios generales del ordenamiento comunitario, provenientes de las tradiciones constitucionales comunes de los Estados. Su naturaleza de principios situaba a los derechos en la visión del TC en un punto intermedio entre la irrelevancia constitucional general del derecho de la UE y una posición similar a la que desde su ratificación ha gozado el CEDH a través del art. 10.2 CE. Los derechos de la UE, interpretados por el TJUE, sirven a la jurisprudencia del TC como pautas interpretativas. Así es como el TC acortaba la distancia entre la posición del CEDH y la atribuida al derecho de la UE, pero solo en lo que a los derechos se refiere. El TC aceptó utilizar no solo como criterios hermenéuticos, sino también de aplicación, normas de derecho europeo, positivas o derivadas de la jurisprudencia del Tribunal Luxemburgo. El primer asunto en que el TC reconoció que el derecho de la UE tenía ese valor en relación con los derechos fundamentales fue la STC 130/1995. Algo después, en la STC 292/2000, el TC conectó este valor con el art. 10.2 de la Constitución y, a partir de ahí, repitió el mismo argumento en diversas sentencias relativas al principio de igualdad y no discriminación, remitiendo a la manera en la que este se recoge en la jurisprudencia del TJUE ${ }^{19}$.

Trascendiendo la cuestión formal de la ubicación de los derechos de la UE en la visión del TC, el señalado predominio económico de las materias reguladas por el derecho europeo hacía inusual que su aplicación diera pie a

ser el juez ordinario a cargo del litigio original el que elevase la cuestión a Luxemburgo, nunca él. Fue cuando el TC afirmó que la única manera en la que su jurisdicción podría verse implicada en la interpretación del derecho de la UE sería en caso de que estuvieran en discusión los derechos fundamentales de la Constitución española (Vidal Prado, 2004: 183). Vid. también las referencias incluidas supra y nota 3.

18 Porque, tal y como explican Cruz Villalón y Requejo Pagés, en el conflicto entre la Constitución nacional y los actos de las Instituciones europeas «las únicas normas constitucionales eventualmente implicadas son las relativas a los derechos fundamentales» (2015: 177).

19 STC 240/1999 de 20 de diciembre; STC 61/2013 de 14 de marzo; STC 71/2013 de 8 de abril; STC 116/2013 de 18 de junio. Vid. Pérez Royo y Carrasco Durán (2014: 872). 
un recurso de amparo, siendo el principio de igualdad en relación con las discriminaciones laborales casi el único y aislado testimonio de la excepción de los derechos (Saiz Arnaiz, 1999: 193). En otro orden de conflictos, se situaba el derecho al juez legal, este en relación con la negativa de un juez ordinario a plantear una cuestión prejudicial sobre la cual el TC se había pronunciado inicialmente, y en sentido tajante, rehusando identificar en tal negativa una ruptura de las garantías propias de la tutela judicial efectiva tal y como aparecen recogidas en el art. 24 de la Constitución ${ }^{20}$. Estos últimos argumentos fueron matizados, y ligeramente alterados en la STC 58/2004, cuando el TC declaró nula una resolución judicial en la que, sin consulta previa al TJUE, y en virtud del principio de primacía, un juez había dejado sin aplicar una ley fiscal por ser contraria al derecho de la UE. El TC consideró que el juez no podía hacer tal cosa sin plantear bien una cuestión prejudicial bien una cuestión de inconstitucionalidad ${ }^{21}$, pues la ausencia de ambas constituía una violación del derecho al juez legal. Los argumentos de esta resolución se repitieron en la STC 194/2006 y en la STC 78/2010, de 20 de octubre ${ }^{22}$.

En una faceta distinta, la excepción de los derechos fundamentales apareció en la STC 145/2012, en la que el TC afirmó que la negativa de un juez

20 En el entendimiento del TC, el procedimiento prejudicial no era una garantía de la Constitución española, por lo que no tenía por qué ser amparada en su sede. Díez Picazo sugiere que este argumento es similar al empleado por el TC ante los recurrentes que consideraban que rehusar el planteamiento de una cuestión de inconstitucionalidad del art. 163 de la Constitución era una violación del derecho a la tutela judicial efectiva del art. 24. El TC no ha llegado a admitirlo, solo que las razones que da en el caso del derecho de la UE son distintas, pues para el TC la cuestión prejudicial no es, o era, hasta Melloni, asunto suyo (Díez Picazo, 1998: 262).

21 Hay que indicar también que, en este caso, el TC también trataba de proteger la norma constitucional de la sumisión de los jueces a la ley, que no les permite dejar a un lado las disposiciones con rango de ley sin una previa revisión constitucional por parte del TC (Biglino Campos, 2007: 10).

22 En ambos casos la controversia versaba sobre una disposición fiscal canaria y adecuación a la Directiva europea de armonización fiscal. Como del ámbito de aplicación de la Directiva estaban excluidos los territorios de las Islas Canarias, el TC determinó que ni era necesaria la consulta al TJUE ni se veían afectadas las garantías de la tutela judicial. Si bien la exclusión del territorio canario de la aplicación de la norma hacía lógica tal conclusión, fue el mismísimo juez constitucional el que resolvió sobre la aplicabilidad de la norma europea, saltándose su propia doctrina sobre su falta de competencia en cuestiones de derecho de la UE. En concreto la STC 194/2006 de 19 de junio fue muy criticada por los expertos a causa de su ambigüedad (Alonso García, 2009: 19). 
a aplicar la jurisprudencia del TJUE era contraria al derecho a la tutela judicial efectiva del art. $24 \mathrm{CE}$. Fue una resolución muy bien recibida por la doctrina y alabada por su acierto al establecer una nueva relación entre justicia constitucional y aplicación del derecho de la UE (Sarmiento, 2013: 875) ${ }^{23}$. Tras esta, y combinando las dos líneas precedentes, la STC 27/2013 razonó que la negativa del Tribunal Supremo a plantear una cuestión prejudicial, siguiendo la doctrina Cilfit de los actos claros ${ }^{24}$, no vulneraba el 24 CE. Pero, en contra de lo que pueda pensarse, esta resolución no era ni una confirmación de la doctrina Cilfit, ni un guiño al TJUE, puesto que en el proceso de origen el juez competente no dejaba de aplicar norma interna alguna y, por tanto, la primacía no entraba en juego. Dicho de otra manera, para el TC la ausencia de consulta al juez europeo no afectaba al derecho al juez legal, quizás porque la cuestión de inconstitucionalidad tampoco era pertinente ${ }^{25}$.

23 El TJUE había declarado, previamente, que una disposición nacional sancionadora era contraria al derecho europeo y, a pesar de tal pronunciamiento, un tribunal español había aplicado la disposición controvertida, ignorando la primacía del derecho de la UE.

24 La doctrina Cilfit se refiere a la teoría de los actos claros, la cual establece los criterios conforme a los que los jueces nacionales pueden prescindir del planteamiento de una cuestión prejudicial ante el TJUE en cuestiones de interpretación del derecho de la UE. Asunto C-283/81, Srl CILFIT y Lanificio di Gavardo SpA vs. Ministry of Health, EU:C:1982:335.

25 Si se contrasta esta última decisión con las STC 194/2006 y 78/2010, se deduce que toda la doctrina del TC español sobre «derecho al juez legal y cuestión prejudicial» se dirige a preservar la disciplina constitucional sobre la aplicación del derecho estatal, no a dar relevancia constitucional a la obligación de colaborar con el TJUE. La cuestión de inconstitucionalidad o la prejudicial, una de las dos, son para el TC requisitos previos a la aplicación del principio de primacía, pero porque el mismo supone el desplazamiento de una ley estatal y el juez ordinario tiene vetada tal acción si no activa, al menos, alguna de las dos consultas previas posibles. En definitiva, no se trata de otorgar estatus constitucional, a través del derecho al juez legal, a la obligación de los jueces de plantear la cuestión prejudicial. Ese mecanismo sigue siendo, para el TC, una garantía que le es ajena. Es el punto de vista de Huelin Martínez de Velasco (2014: 54). 


\section{INFLEXIONES E INFLEXIBILIDADES}

Y, por supuesto, Melloni. Si en la jurisprudencia constitucional sobre el derecho de la UE había habido ya un punto de inflexión, y a partir de la STC 58/2004 se había empezado a considerar que el TC estaba más cerca de aceptar la jurisdicción prejudicial del TJUE y hasta de utilizarla él mismo ${ }^{26}$, el Asunto Melloni parecía que iba a ser «el asunto». Sin embargo, en su sentencia final, el TC apenas respondió más que a la ausencia de vulneración del derecho a un juicio con todas las garantías del 24.2 CE, defraudando expectativas de que la cuestión prejudicial se consolidase como un instrumento de armonización, y diálogo, entre el TJUE y el TC.

Los antecedentes del ATC 86/2011 parecían apuntar lo contrario, al menos en cierto sentido. En su STC 199/2009, el juez constitucional español había otorgado el amparo a un condenado en rebeldía, como Stefano Melloni sujeto a una Orden de Detención Europea (ODE), por una infracción indirecta del contenido absoluto del derecho de defensa. Contra lo dispuesto en la norma de transposición, y en la Decisión Marco reguladora de la ODE, como no era posible exigir la revisión de la condena una vez que el individuo fuera entregado al Estado solicitante, el TC anuló la decisión de la Audiencia Nacional. Eso sí, para cuando el TC dictó su sentencia, la ODE ya había sido ejecutada, por lo que la resolución del juez constitucional no creó problemas relativos al cumplimiento del derecho de la UE. Pero sí provocó discrepancias. En particular, dos magistrados del TC, en voto particular, consideraron que debía haberse interpuesto una cuestión prejudicial, cosa que no se efectuó. Dos años después, cuando llegó la demanda de amparo del señor Melloni, la Decisión Marco de la ODE acababa de ser enmendada, incluyendo algunas precisiones sobre las condenas in absentia. La nueva regulación podía cuestionar la jurisprudencia previa del TC. En tal situación, con los antecedentes comentados y temiendo que la Audiencia Nacional fuera la que remitiese la cuestión prejudicial, tras una posible sentencia de amparo estimatoria, el TC remitió su primera cuestión prejudicial (Díez-Hochleitner Rodríguez, 2014: 169).

26 Se elucubró que podría hacerlo bajo dos premisas: una, que hubiera una vulneración de un derecho fundamental anudada a la aplicación directa de una norma de derecho de la UE; y la otra, que esa vulneración concreta afectara a una disposición de especial significación en el sistema europeo (Vidal Prado, 2004: 188). 
Resistiéndome a entrar en los pormenores del Asunto Melloni, extensamente comentados $^{27}$, haré un par de apreciaciones sobre sus virtualidades y carencias. Con carácter general, señalaré como positiva la asunción por parte del TC de la necesidad de elevar la consulta prejudicial en un caso relativo a los estándares de protección de los derechos fundamentales y, en definitiva, a la interpretación del art. 53 de la Carta ${ }^{28}$. La valoración negativa la reservo para la manera en la que el TC integra en su STC 26/2014 el juicio interpretativo de la Sentencia del TJUE de 26 de febrero de 2013, pues si bien el TC acepta el resultado que se imponía en aquella, no lo hace como consecuencia de una obediencia a los dictados del TJUE, sino según una reelaboración propia, conforme a su parámetro constitucional de control (Requejo Pagés, 2015: 500). En especial destaca la integración que no hace sobre el alcance de los artículos 47 y 48 de la Carta en relación con las condenas en rebeldía.

Esa carencia, a mi entender, trae causa de ciertos puntos ciegos en la argumentación del TC. En primer lugar, la utilización del art. 10.2 CE, para colocar a la Carta de Derechos al mismo nivel que los derechos de la UE antes de la Carta, ignora que esta tiene idéntico rango normativo que los tratados y que para ella también cuenta el principio de atribución, y, por ende, el de primacía. La jurisprudencia del TJUE sobre la Carta tiene para el TC, en lo que a su jurisdicción se refiere, el mismo valor, interpretativo, que tiene la del Tribunal Europeo de Derechos Humanos (TEDH). En segundo lugar, hay una única mención en la resolución del TC al art. 93 de la Constitución, que es la llave de la transferencia de competencias constitucionales, y la función de tal mención es solo la de recordar la doctrina de los contralímites, reproducida a partir de la establecida por el TC en su Declaración 1/2004 (FJ 4). Parece, cuando menos, indicativo de una toma de posición, defensiva, ante las actuaciones supranacionales en materia de derechos fundamentales. En tercer lugar, y volviendo al principio, los arts. 47 y 48.2 de la Carta, de específica aplicación al caso, son desplazados por el 24.2 CE. Para el TC no tienen relevancia las reglas de aplicación establecidas en el 51 de la Carta, que exigen la priori-

27 Remito a algunos trabajos que ya incluyen apreciaciones sobre la sentencia final del TC, puesto que la bibliografía sobre el auto de planteamiento también fue profusa, así como la que comentaba laSTJUE de 26 de febrero de 2013, C-399/11, EU:C:2013:107. Entre otros: Torres Pérez (2014: 308-331), Martín Rodríguez (2014: 603-622), Gordillo Pérez y Tapia Trueba (2014) y Arzoz Santisteban (2015: 87 y ss.).

28 Parece que, en el caso, la relación con la protección de un derecho fundamental hacía que una posible cuestión prejudicial del TC fuera consistente con sus argumentos previos sobre la relación entre el derecho de la UE y su propia competencia jurisdiccional (Arroyo Giménez, 2011: 15). 
dad de sus cláusulas cuando los Estados miembros apliquen derecho de la UE. Que la ejecución de una ODE es aplicación del derecho de la UE es una realidad incontrovertible. El TC no necesitaba la doctrina Äkerberg ${ }^{29}$ para saber eso. Por último, y en cuarto lugar, el TC reinterpreta el contenido constitucional del 24.2 CE, olvidando ese contenido absoluto previamente declarado en su doctrina sobre extradición por condenas en rebeldía. Y lo hace en contradicción con el 53 de la Carta, que avala el mantenimiento de estándares nacionales de garantía fuera de la aplicación del derecho de la $\mathrm{UE}^{30}$.

Coincido, pues, con las apreciaciones de los votos particulares al considerar que, si el derecho de la UE es aplicable, la Carta tiene naturaleza imperativa, y no solo interpretativa; y la sentencia del TJUE, naturaleza ejecutiva ${ }^{31}$. Es cierto que, en otra línea, hay quienes responsabilizan al TJUE de haber provocado una reacción defensiva del TC, sobre la base de que la Sentencia Melloni del juez europeo era demasiado atrevida al contradecir abiertamente la jurisprudencia previa del juez constitucional sobre el contenido absoluto

29 Doctrina contenida en la sentencia del Asunto C-617/10, Äkerberg Fransson, EU:C:2013:105. El fallo se dio a conocer en la misma fecha que el del Asunto Melloni. Determina la doctrina del TJUE sobre la intepretación del art. 51 de la Carta para casos en los que la aplicación del derecho de la UE a través de una actuación nacional se salga de lo evidente (Iglesias Sánchez, 2013: 1157-1175; Épiney, 2014 : 291 y ss.).

30 Y es que el TC ya había hecho una interpretación del 53 de la Carta en su DTC 1/2004 muy distinta a la que realiza el TJUE en su Sentencia Melloni (Quadra-Salcedo Janini, 2015: 36). A partir de Melloni, la doctrina del contenido absoluto del derecho a la defensa cambia para todos los casos. Ya no es aplicable si el convicto, al menos, ha tenido la oportunidad de ser representado por un abogado. Así, esas garantías se recortan también para extradiciones a países terceros, que no tienen por qué cumplir los cánones del reconocimiento mutuo, dados por supuestos entre los Estados miembros de la UE (Besselink, 2014: 533).

31 Además, la decisión del TJUE en Melloni se refería al caso concreto y no tenía por qué haber desembocado en una reinterpretación del art. 24.2 de la Constitución española. Los argumentos relativos a la interpretación de la sentencia del TJUE a través del 10.2 de la Constitución están en el fundamento jurídico 3. La magistrada Adela Asúa Barratia critica esos argumentos en el primer apartado de su voto particular: «[...] la sentencia del Tribunal evita las cuestiones centrales [relativas a la función y a la protección de los derechos de la Carta]. En lugar de eso, se ciñe a una doctrina constitucional previa a través de la cual el Tribunal ha repetido que el Derecho europeo no es un asunto de relevancia constitucional, que el TC no tiene la función de garantizar la aplicación del derecho de la UE y que el derecho de la UE solo sería relevante según lo dispuesto en el art. 10.2 de la Constitución, esto es, en relación con la interpretación del ámbito de aplicación de los derechos fundamentales constitucionales». 
del derecho de defensa. Según esta perspectiva, el TC se habría encontrado en una encrucijada, condicionado por la tensión competitiva con la Audiencia Nacional, y el TJUE no habría sabido apreciar las implicaciones internas de su

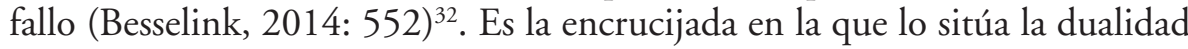
jurisdiccional interna en materia de derechos fundamentales, complicada por la superposición de una tercera jurisdicción, la supranacional, con una competencia pujante en materia de derechos fundamentales y con una Carta propia que aplicar. Melloni confirma la impresión de «cortocircuito» cuando se constata que el TC se opone a asumir que hay una atribución de competencias en materia de derechos fundamentales y que esta otorga a las disposiciones de la Carta, y a la interpretación del TJUE, un carácter imperativo no solo, y esta es la cuestión crucial, de cara a su aplicación por parte de los jueces y tribunales, sino también en lo que se refiere a la su propia labor de tutela individual de derechos fundamentales. En este punto, la inflexibilidad del TC en relación con lo constitucional-formal da pie a una visión desintegrada de la aplicación de los derechos fundamentales europeos, que van a tener una fuerza normativa distinta según ante qué jurisdicción, constitucional u ordinaria, se presenten.

\section{LA DOBLE VISIÓN DEL TC}

Melloni contrasta, sin contradecirla, con el resto de la jurisprudencia del TC en cuestión de tutela de derechos europeos. Y es que, en su sentencia, el juez constitucional toma posición, y distancia, sobre la aplicación de la Carta de Derechos, con el resultado de establecer una diferencia en la efectividad de esta según su aplicabilidad se cuestione en sede constitucional o ante la jurisdicción ordinaria. La doctrina sobre los derechos fundamentales como excepción a la irrelevancia del derecho europeo, esbozada en el epígrafe anterior, sirve para ahondar en el contraste. Lo hemos visto con el ejemplo de cómo el TC insiste en que el desarrollo iusfundamental que contienen las regulaciones europeas sobre igualdad es de obligado seguimiento para jueces y tribunales cuando dirimen un conflicto enmarcado en parámetros de derecho de la UE. En tales casos, y en determinadas circunstancias, la referencia al TJUE, bien mediante la cuestión prejudicial bien con el seguimiento de su jurisprudencia, se convierte en obligatoria para la jurisdicción ordinaria, se consolida como

32 La idea es que, tal y como se le achacó con Landtová y el TC checo, el TJUE habría errado al no considerar debidamente la situación nacional interna en esas controversias judiciales en las que se veía envuelto el derecho de la UE. Asunto C-399/09, Marie Landtová vs. Česká správa socialního zabezpečení, EU:C:2011:415. Vid. Alonso García (2012) y Anagnostaras (2013: 959-973). 
una garantía aneja al 24.1 CE y se declara coherente con la atribución de competencias autorizada por el $93 \mathrm{CE}$.

Sin embargo, en sede constitucional, las normas iusfundamentales de la UE se integran a través del 10.2 CE. Los jueces y tribunales se someten a los contenidos iusfundamentales europeos y al mandato del 51 de la Carta, pero el TC solo está vinculado por las disposiciones iusfundamentales de la Constitución y por la cláusula de integración interpretativa del $10.2 \mathrm{CE}$. El contraste entre la STC 26/2014, Melloni, y la reciente STC 232/2015, sobre igualdad en retribuciones funcionariales, ilustra esta situación. En la segunda de ellas, el TC insiste en que el juez debe resolver el caso conforme al sistema de fuentes establecido, dentro del cual se encuentran las normas de los tratados y del derecho derivado de la UE (FJ 4). Existiendo jurisprudencia consolidada del TJUE sobre el asunto controvertido, la cuestión prejudicial no se hace imperativa, pero sí la aplicación del principio de primacía del derecho de la UE. Cuando "exista una interpretación auténtica efectuada por el propio Tribunal de Justicia de la Unión Europea», la primacía del derecho de la UE obliga a seguirla. "En estos casos», continúa exponiendo el TC, «el desconocimiento y preterición de esa norma de derecho de la UE, tal y como ha sido interpretada por el Tribunal de Justicia, puede suponer una "selección irrazonable y arbitraria de una norma aplicable al proceso», lo cual puede dar lugar a una vulneración del derecho a la tutela judicial efectiva" por los jueces y tribunales ordinarios (FJ 5).

La apreciación consecuente es que el TC mantiene una doble visión de la relación con el derecho de la UE en materia de derechos fundamentales, una para él y otra para la jurisdicción ordinaria. Tal apreciación tiene fundamento en su comprensión formal de la relación de la Constitución con los tratados y del efecto de aquella sobre su propia jurisdicción. Pero también tiene consecuencias sobre su función de tutela de derechos constitucionales.

Por una parte, la doble visión impone una bifurcación. La jurisprudencia de referencia sobre la dimensión sustantiva de ciertos derechos, según sean constitucionales o europeos, se desdobla. Y eso ocurre por más, y a pesar de, la identidad de contenidos básicos entre unos y otros derechos. Es llamativo que en la STC 232/15 el juez constitucional reconozca que el recurso de amparo fue admitido porque podría permitirle valorar si procedía o no mantener, o matizar, su doctrina «acerca de la proyección del derecho a la igualdad entre situaciones funcionariales, y en concreto entre los funcionarios de carrera y los funcionarios interinos, establecida desde la STC 7/1984, de 7 de enero", para luego avisar que eso no significaba necesariamente que fuera a llevar a cabo tal valoración, como, en efecto, no hizo por cuestiones derivadas de la lógica hermenéutica propia de su función (FJ 2). 
Por otra parte, se consolida la posición del juez ordinario como garante básico de la tutela individual de los derechos fundamentales de la Carta, así como lo hace la del TJUE en la tutela objetiva de aquellos. El amparo constitucional en conflictos de este tipo queda como un recurso extraño al derecho de la UE, pues para el TC es una garantía exclusiva, subjetiva y objetiva, de los derechos constitucionales. El sujeto que solicita la tutela en amparo del TC debe calcular el riesgo de que, incluso mediando una remisión prejudicial, este se resista a asumir la jurisprudencia europea de referencia sobre el derecho fundamental alegado. Puesto que al juez constitucional no le vincula el mismo sistema de fuentes que al juez ordinario, ni la primacía ni la jurisprudencia del TJUE pueden gobernar su acción tutelar de derechos. Por tanto, el amparo constitucional reforzará los derechos europeos cuando sea el juez ordinario el que desoiga los mandatos de las normas de la UE, y su interpretación por el TJUE, pero no garantiza que ocurra lo mismo cuando el asunto requiera una intermediación distinta por parte del TC.

\section{LOS DERECHOS FUNDAMENTALES DE LA UE Y LA JURISDICCIÓN ORDINARIA: PEQUEÑO REPERTORIO}

Mientras tanto, es decir, mientras el TC ha afirmado su posición de nogarante formal de los derechos de la Carta, los jueces y tribunales de la jurisdicción ordinaria se han hecho con la nueva norma y la han incorporado dentro del canon de aplicación del derecho de la UE. Un análisis conjunto de la actuación de los jueces estatales y de la jurisprudencia del TJUE en este ámbito, que de nuevo por limitaciones de extensión no tendrá más remedio que ser superficial, muestra la buena disposición de los primeros a aplicarla, así como a consultar al TJUE cuando a tal fin sea necesario. Además, lo que es de gran interés, los jueces españoles se muestran favorables a profundizar en la virtualidad de la Carta como un instrumento de tutela de los derechos cuando estos, por su relación singular con el derecho de la UE, adquieren contenidos y aplicaciones específicas. Es así como, ante el derecho europeo, la jurisdicción ordinaria se hace preguntas que difícilmente se haría en relación con el desarrollo normativo de los derechos de la Constitución y también como recibe del TJ matices sobre esos mismos derechos que difícilmente podrían propiciarse con su desarrollo en el sistema normativo interno ${ }^{33}$.

33 La vinculación del derecho de la UE con las competencias propias del proyecto de integración determina líneas de interpretación de los derechos fundamentales que son específicas de la jurisprudencia del Tribunal de Justicia y en las que la necesidad de 


\section{TUTELA JUDICIAL EFECTIVA}

De la naturalidad con la que los jueces estatales manejan el derecho de la UE, con sus altibajos, avances y retrocesos, y de cómo hacen uso de la cuestión prejudicial dan cuenta distintos estudios doctrinales, de los que se infiere que el grado de asimilación de la función europea de nuestros jueces está dentro de la media del resto de la $\mathrm{UE}^{34}$. En la experiencia española reciente, considero que han sido especialmente significativas, en muchos sentidos, las remisiones prejudiciales relacionadas con el procedimiento de ejecución hipotecaria. $\mathrm{Me}$ refiero, en concreto, a los asuntos Aziz y Sánchez Morcillo y, recientemente, Ibercaja; este último resuelto mediante un auto que traslada a un nuevo supuesto la doctrina de las sentencias anteriores ${ }^{35}$. Todos son casos relativos a las cláusulas presuntamente abusivas en los contratos hipotecarios. En lo que aquí interesa, muestran cómo los jueces comprenden que el derecho de la UE ofrece vías de tutela de los derechos de los deudores hipotecarios que aparecen cerradas en sede constitucional.

En efecto, la cuestión del Asunto Aziz se plantea superando el obstáculo que suponía la existencia de una jurisprudencia constitucional previa, que validaba la conformidad constitucional del procedimiento de ejecución original de la legislación española ${ }^{36}$. En su turno, la de Sánchez Morcillo también

convergencia con las otras líneas, las propias de la justicia constitucional estatal y la del Tribunal de Estrasburgo, nunca se ha planteado como un absoluto (Azpitarte Sánchez, 2015: 254 y ss.).

34 Pueden consultarse los análisis anuales que publica la Revista Española de Derecho Comunitario Europeo, en los que se toma el pulso a la aplicación judicial del derecho de la UE en España. Sobre los altibajos, avances y retrocesos, resulta de gran interés el trabajo de Sarmiento (2012: 19 y ss.). Sobre la actividad de los jueces españoles en torno al derecho de la UE, vid.: Ruiz-Jarabo Colomer (2011) y el clásico Alonso García (2003).

35 Asunto C-415/11, Aziz, EU:C:2013:164; Asunto C-169/14, Sánchez Morcillo, EU:C:2014:2099; Asunto C-613/15, Ibercaja Banco, ECLI:EU:C:2016:195.

36 Al mismo tiempo que el TC confirmaba en su ATC 113/2011 de 19 de julio de 2011 su jurisprudencia sobre la constitucionalidad del procedimiento de ejecución hipotecaria de la LEC, cosa que hacía inadmitiendo una cuestión de inconstitucionalidad de un juez de primera instancia de Sabadell, un juez de lo mercantil de Barcelona remitía al TJUE la cuestión prejudicial del Asunto C-415/11, Aziz, resuelta un par de años después mediante la STJUE de 14 de marzo de 2013, EU:C:2013:164. El auto de remisión de la cuestión prejudicial se fecha también el 19 de julio de 2011 (Medina Guerrero, 2015: 264 y ss.). 
se eleva tras la inadmisión por parte del TC de distintas cuestiones de inconstitucionalidad, en las cuales los jueces se preguntaban si las reformas implementadas tras la Sentencia Aziz respetaban realmente los principios de igualdad en conexión con el derecho a la tutela judicial efectiva ${ }^{37}$. El TC no entró en el fondo, pero el TJUE sí lo hizo.

Por último, si bien es cierto que en el primero de los asuntos, Aziz, las preguntas prejudiciales no se referían expresamente al art. 47 de la Carta, a la tutela judicial efectiva, no lo es menos que la respuesta del TJUE tiene en primer plano la sustantividad de las garantías del ejecutado, el principio de efectividad de la Directiva sobre las cláusulas abusivas y su traducción en la exigencia de compensar en el terreno procesal la situación de inferioridad, desigualdad de armas, en la que se encuentra el consumidor contratante de hipoteca (Medina Guerrero, 2015: 279). Una visión bastante diferente a la sostenida por el TC en su intacta doctrina.

\section{IGUALDAD Y NO DISCRIMINACIÓN}

Sobre los derechos relacionados con la igualdad y no discriminación, ya se desgranaban algunas pistas en el epígrafe anterior. El TC ha admitido la virtualidad interpretativa de las normas comunitarias en materia de igualdad a la hora de dirimir recursos de amparo, de conformidad con el 10.2 CE, si bien con matices y limitaciones en lo que a su propia función como garante constitucional se refiere. La STC 232/2015 mostraba que admitir la virtualidad hermenéutica del derecho europeo aún no significa que se haya modificado su línea jurisprudencial, en concreto la relacionada con el reconocimiento de ciertas situaciones en el ámbito del funcionariado. Así, si sigue vigente la doctrina de la STC 7/1984, no es tan de extrañar que un Tribunal Superior de Justicia intente hacer un acople entre la jurisprudencia del TJUE en la materia y la del TC, y evite la cuestión prejudicial, como ocurrió en los antecedentes de la STC 232/2015.

Pero tampoco es tan de extrañar la actitud inversa: que un Tribunal Superior de Justicia decida plantear una cuestión prejudicial ante la duda de si la jurisprudencia constitucional patria puede ir en contra de la Directiva de igualdad y, una vez obtenida la respuesta, aplique una decisión del juez europeo que contradiga la doctrina del TC español. Los asuntos Cordero Alonso y Rosado Santana son dos casos, señeros, de referencia, idóneos para ilustrar

37 Si bien es cierto que el TC las inadmite por no adecuarse al juicio de relevancia que la norma cuya constitucionalidad se discuta debe pasar, cuando se trata de una cuestión de inconstitucionalidad (Díez García, 2014: 218 y ss.). 
esto $^{38}$. Parece, entonces, que al juez constitucional no le resulta problemático que el ordinario siga la jurisprudencia de Luxemburgo, siempre y cuando se trate de una línea consolidada o, en caso contrario, siempre que se plantee, bien la cuestión prejudicial, bien la de cuestión de inconstitucionalidad. ¿Quiere eso decir que el art. 5.1 de la LOPJ no vincula al juez ordinario cuando se dan las circunstancias confirmatorias de la doctrina europea sobre igualdad? A mí no me queda claro, y eso que no soy juez, pero desde mi perspectiva, y si lo fuera, optaría por plantear la prejudicial, siquiera por ser donde menos riesgo corro de llevarme un tirón de orejas si finalmente el asunto acaba en amparo.

\section{PROTECCIÓN DE DATOS}

Por último, aunque el repertorio casuístico no se cierra con esto, me gusta especialmente el tema de la protección de datos de carácter personal, donde creo que se constata con claridad que es el TJUE el que ostenta la condición de garante objetivo, y por antonomasia, del derecho fundamental. El TJUE tiene una sólida jurisprudencia basada en la Directiva y ahora también en los derechos de los arts. 7 y 8 de la Carta, una jurisprudencia que yo calificaría como de vanguardia y que contrasta con el esquemático tratamiento que el TC le ha dado a este derecho ${ }^{39}$. Se comprueba también que, para los jueces españoles, el intérprete de referencia en relación con la protección de datos es el de Luxemburgo. No creo que haya ninguna duda al respecto y esto se reafirma tanto cuando se trata de asuntos directamente relacionados con la transposición de una directiva al ordenamiento interno, como en casos relativos a su directa aplicación.

En el primer grupo se encuentra la pregunta prejudicial del Tribunal Supremo en el Asunto Asnef ${ }^{40}$. La norma española de trasposición había alterado los márgenes de la Directiva, lo que había reforzado la protección de la

38 Asunto C-81/05, Cordero Alonso v Fondo de Garantía Salarial (Fogasa), EU:C:2006:529; y Asunto C-177/10, Francisco Javier Rosado Santana vs. Consejería de Justicia y Administración Pública de la Junta de Andalucía, EU:C:2011:557. Sobre la primera, vid. Álvarez-Ossorio Micheo (2008: 118) y Díez-Hochleitner (2013: 32).

39 Tampoco hay lugar para profundizar en esta cuestión. Remito, como compendio crítico de jurisprudencia, a Aguado Renedo (2010).

40 Asuntos acumulados C-468/10 y C-469/10, Asnef, EU:C:2011:777. La remisión prejudicial al TJUE la hace la Sala Tercera del Tribunal Supremo, a consecuencia de un recurso contencioso-administrativo contra diversos artículos del Real Decreto $1720 / 2007$. 
intimidad y de los datos personales. Esos refuerzos normativos ceden ante la doctrina armonizadora del TJUE, que expone una serie de criterios de ponderación en la relación entre los intereses jurídicos protegidos por los derechos y deja esos criterios fuera de los márgenes de apreciación de los Estados miembros. En el segundo grupo debo citar el estelar Asunto Google Spain ${ }^{41}$, en el que la Audiencia Nacional acude al TJUE para dirimir la existencia de contenidos iusfundamentales tan novedosos como el derecho al olvido, en relación con los datos de carácter personal. El TJUE realiza una sentencia rompedora en la que establece la responsabilidad de los motores de búsqueda por la lesión de los derechos de los arts. 7 y 8 de la Carta.

Como muestra de la capacidad de proyección de la jurisprudencia del TJUE sobre protección de datos, apunto una sentencia del Tribunal Supremo de octubre de $2015^{42}$, en la que el Alto Tribunal aplica la doctrina derivada del caso Google para ponderar entre la situación de las hemerotecas digitales y la de los sujetos cuyos datos figuren en estas. Conforme al criterio de veracidad, como clásico elemento de refuerzo de la protección de libertades informativas $^{43}$, el Supremo confirma que las hemerotecas digitales no tienen por qué bloquear informaciones veraces del pasado en sus buscadores internos. Conforme a la doctrina de la responsabilidad por los resultados de indexaciones que afecten a la reputación del titular de los datos, las hemerotecas digitales sí tienen que implementar medidas para que el tratamiento de los datos se lleve a cabo de tal manera que se impida su localización por motores de búsqueda externos. Las hemerotecas digitales son, por tanto, responsables. Me pregunto qué haría el TC si le llegara este asunto en amparo, con el diario digital recurriendo sobre la base del 20.1.d) CE. Sobre todo teniendo en cuenta que el proceso trae causa de una demanda de protección civil del honor conforme a la LO 1/1982, en lugar de ser un contencioso relacionado con la aplicación directa de la LOPD y, en consecuencia, de la Directiva, siendo los matices diferentes, como diferente es la jurisprudencia del TC sobre honor e intimidad de la que ha hecho sobre protección de datos. Y así, aquí lo dejo.

41 Asunto C-131/12, Google Spain, EU:C:2014:317. Sobre esta sentencia también hay un curioso volumen de literatura doctrinal. Como muestra: A. Rallo (2014: 259284), Simón Castellano (2015: 97 y ss.), Azurmendi (2015: 273-310), Crowther (2014: 892-893), Hardy (2014: 879-897) y Koutrakos y Shuibhne (2014: 293-294).

42 Sentencia de la Sala de lo Civil del Tribunal Supremo de 15 de octubre de 2015 , ES:TS:2015:4132.

43 Cuestión también muy tratada y de manera reciente por Vázquez Alonso (2014: 389). 


\section{CONCLUSIONES: BAJO LA VISIÓN SUPRANACIONAL Y DESDE LA VISIÓN DEL JUEZ ORDINARIO}

Desde la visión del TJUE, en tanto en cuanto las decisiones del TC no han creado por el momento problemas de aplicación del derecho de la UE, y no ha habido una confrontación directa con su jurisprudencia, la situación interna es completamente extraña a él. Es obvio que el TC se mantiene «al margen» de los parámetros ofrecidos por el TJUE sobre la implementación de los derechos de la UE cuando los Estados actúan en aplicación de normas europeas. Tales parámetros fueron trazados a partir de la Sentencia Wachauf, en la que por primera vez se aplicaron los derechos europeos a una actuación nacional que, fuera de lo evidente, más bien se situaba dentro de una comprensión amplia del marco de proyección del derecho de la UE (Azpitarte Sánchez, 2002: 138 $)^{44}$. La dicción literal del art. 51 de la Carta, «cuando apliquen», que en un primer momento pareció podía restringir el ámbito de actuación de los derechos europeos, finalmente, con Äkerberg, quedó en una restricción aparente ${ }^{45}$. Así, aplicar los derechos de la UE, para el TJUE, es exigido siempre que se esté dentro del ámbito de proyección de su Derecho y esto, lejos de una cuestión de conformidad del resultado (Arzoz Santisteban, 2015: 99), es un mandato imperativo que hace el sistema normativo europeo al sistema institucional de los Estados miembros, incluidos los tribunales constitucionales.

Desde el vértice inferior, desde la posición del juez ordinario, las cosas están también más o menos claras. Están obligados a seguir la jurisprudencia del TJUE en materia de derechos fundamentales cuando apliquen el derecho de la UE, en un sentido amplio. Están obligados a implementar los estándares de protección de la Carta cuando apliquen el derecho de la UE, en un sentido amplio. Mientras no haya una resolución distinta al respecto por

44 Asunto C-5/88, Wachauf, EU:C:1989:321. Lo interesante del asunto, más allá de su enrevesado planteamiento jurídico sobre indemnizaciones por cese de explotaciones agrícolas, es que los derechos fundamentales que deben ser tenidos en cuenta como parámetros de la actuación de los Estados no se derivan de sus constituciones, sino del propio sistema normativo europeo. Sigue esta línea el Asunto C-2/92, Bostock, EU:C:1994:116. Vid. Groussot et al. (2011: 5).

45 En su origen, se achacó al 51 de la Carta su condición restrictiva de la jurisprudencia Wachauf (Matia Portilla, 2002: 160). La intención restrictiva de los derechos de la Carta en el 51 queda, tras Äkerberg, como aparente (Iglesias Sánchez, 2012: 1584). 
parte del TC, el reproche básico que les llegaría del juez constitucional a través de amparos estimatorios se produciría cuando se hubiese ignorado la posición del derecho europeo en el sistema de fuentes, incluida la jurisprudencia del TJUE, o cuando no se haya consultado al TJUE y, sin mediar tampoco cuestión de inconstitucionalidad, se haya desplazado una ley estatal aplicable. El amparo constitucional se hace inoperativo para reclamar la lesión de contenidos sustantivos de los derechos de la $\mathrm{UE}^{46}$. Si nos guiamos por lo que hace el TC en la STC 232/2015, la retroacción de las actuaciones, como medida reparadora de la lesión del 24.1 CE, devuelve la cuestión de la aplicación del derecho de la UE y de la ponderación de los contenidos iusfundamentales europeos al juez a quo. Por tanto, la doctrina del TJUE se erige en referente suprema y el juez europeo, como debe ser, en máximo garante objetivo de los derechos europeos, al que los jueces deben seguir en su tutela subjetiva.

El único pero, hasta ahora, es que la doctrina constitucional sobre contenidos iusfundamentales parejos a los de los derechos de la Carta queda estacionada mientras tanto, como hemos comprobado con distintos supuestos: tutela judicial efectiva, igualdad y no discriminación, protección de datos. En consecuencia, para la jurisdicción ordinaria se consolidan estándares de protección distintos para la tutela de los derechos, según se encuentren ante controversias puramente internas, de derecho estatal, o ante otras en las que sean de aplicación normas del sistema de la UE. Esto, en determinados casos, sería un segundo pero. La realidad es que tutelar los derechos de la UE supone incorporar los intereses del derecho europeo, que pueden ser distintos de los del derecho estatal (Ugartemendia Eceizabarrena, 2013: 411).

Es evidente que los tribunales constitucionales, según el modelo europeo de control de constitucionalidad concentrado, residenciado en un órgano distinto del poder judicial, nacen antes de la UE, se diseñan para cumplir un propósito que nada tiene que ver con la aplicación de normas supranacionales. Y se superponen, como jurisdicción de excepción, a un sistema judicial cuyo margen de autonomía en la aplicación jurisdiccional de la Constitución se ve limitado por la mera existencia de aquellos. Al integrarse ambas jurisdicciones, la constitucional y la ordinaria, en otro sistema materialmente constitucional, el de la UE, que por una parte los

46 De la Quadra-Salcedo Janini considera, incluso, que sería conveniente una abstención en estos asuntos por parte del TC, al menos cuando no hubiera margen de apreciación, estimulando la responsabilidad de los jueces ordinarios en la aplicación del derecho de la UE (2015: 54). 
abarca a ambos, pero en el que, por otra parte, los jueces no sufren las mismas limitaciones en su función tutelar, los elementos contra natura que hay en modelo europeo de control de constitucionalidad le pasan a este su factura $^{47}$.

Pero tampoco hay que ser dramáticos, la situación dista de ser insostenible. Todo apunta a que el TC va a hacer un uso muy limitado de la cuestión prejudicial y a que los jueces van a realizar un uso habitual de esta en materia de derechos fundamentales. Esto consolidará dos repertorios distintos de jurisprudencia para contenidos iusfundamentales parejos: los de la Constitución y los de la Carta. El sistema de tutela individual de derechos, basado en el juez ordinario como su garante natural, se verá así reforzado, pues si a la situación de pluralidad jurisdiccional se unen las pretensiones, no del todo radicales, de objetivar el amparo constitucional, la acción tutelar de los jueces adquirirá mayor protagonismo.

Por otra parte, en los casos, que creo que serán pocos, en los que el TC remita cuestiones prejudiciales al TJUE, será este el que tenga que dirimir si mantiene su jurisprudencia sobre la infraconstitucionalidad, la irrelevancia y la incorporación de la Carta y de la doctrina del TJUE como meros cánones interpretativos o si se atreve a asumir un rol cooperativo, lo que redefinirá su posición. Si se mantiene en la primera de las hipótesis, significaría también una alteración en la naturaleza originaria de la cuestión prejudicial. Es decir, si el TC pregunta al TJUE cuando tenga dudas sobre la compatibilidad entre estándares de protección de derechos, pero con la finalidad de dar garantía objetiva a los constitucionales, pondría el mecanismo prejudicial al servicio del Título I, según el 10.2 CE, en lugar de al servicio del derecho de la UE y de la Carta, conforme al 267 TFUE. Esto modificaría nuestro diagrama de cabecera justo en la cumbre, justo donde se cortocircuitaba el diagrama anterior.

47 Sobre esos elementos contra natura, en su obra Los derechos y los jueces, Bartolomé Clavero advertía que los jueces ordinarios no se hallan en nuestro sistema verdaderamente vinculados a los derechos, al estarlo en primer lugar a la ley y al estar limitados por las constricciones de ese «artificio» que es el sistema de control de constitucionalidad concentrado (Clavero, 1988: 89). 
Diagrama 4: Jurisdicciones y Tutela de Derechos Fundamentales

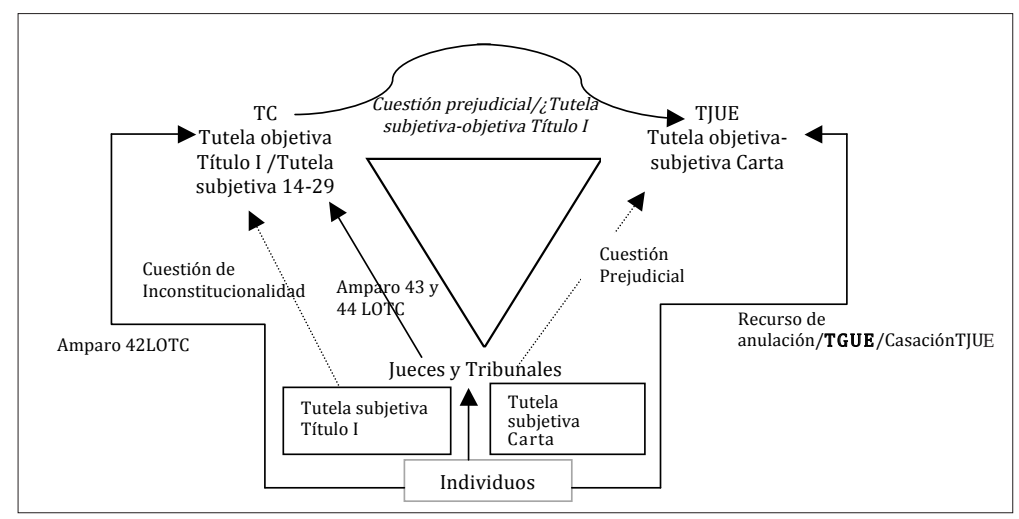

Y la cuestión más esperada es la siguiente: ya que el TC es el que crea el "cortocircuito», ¿tendría que modificar su postura ante el derecho de la UE? Pues, sinceramente, no sabría qué decir al respecto. Es cierto que una hermenéutica cooperativa, sobre la base de una concepción no exclusivamente procedimental del art. $93 \mathrm{CE}$, facilitaría las cosas. Pero también es cierto que ni la configuración de su función jurisdiccional lo lleva a ello, ni está claro que las ideas de interacción y metaconstitucionalidad se puedan asumir por parte de los aplicadores del derecho con la naturalidad con la que lo hacemos en otros ámbitos. Si se piensa un poco, de hecho nada parecido se espera de los jueces ordinarios, cuyas líneas de actuación en relación con el derecho de la UE han de seguir las pautas propias de este. Tanto el TJUE como el TC se ocupan de que esa cuestión suscite las menos dudas posibles. Y lo de la metaconstitucionalidad tampoco es algo que practique con solvencia el Tribunal de Justicia, fiel a sus métodos de interpretación autóctonos, diseñados para favorecer los objetivos de los Tratados. Al TC se le pide un cambio en la comprensión normativa del 93 CE. También al TJUE se le hace esa demanda en relación con el principio de identidad nacional del 4.2 TUE, pues la subsidiariedad del 5.1 TUE parece un caso perdido. Si en sentencias venideras vemos alguno de esos giros, repensaremos las relaciones entre los vértices del triángulo. Mientras tanto, las cosas están así.

\section{Bibliografía}

Aguado Renedo, C. (2010). La protección de los datos personales ante el Tribunal Constitucional español. Cuestiones Constitucionales, Revista Mexicana de Derecho Constitucional (23), 3-25. Disponible en: http://biblio.juridicas.unam.mx/revista/CuestionesConstitucionales/indice.htm? $\mathrm{n}=23$. 
Alonso García, R. (2003). El juez español y el derecho comunitario. Valencia: Tirant lo Blanch.

- (2009). Cuestión prejudicial europea y tutela judicial efectiva (a propósito de las SSTTCC 54/2004, 194/2006 y 78/2010). Cuadernos de Derecho Público (38), 11-30.

- (2012). Guardar las formas en Luxemburgo. Revista General de Derecho Europeo (28).

Disponible en: http://www.iustel.com/v2/revistas/detalle_revista.asp?id=13.

- (2014). El juez nacional en la encrucijada europea de los derechos fundamentales. Cizur Menor: Thomsom Reuters.

Alter, K. J. (2001). Establishing the Supremacy of European Law. Oxford y New York: Oxford University Press.

Álvarez-Ossorio Micheo, F. (2008). El sistema multinivel de protección de derechos fundamentales. Un análisis desde la Carta de Derechos Fundamentales de la Unión Europea. En Carmona Contreras A. (ed.). La Unión Europea en perspectiva constitucional (pp. 113126). Cizur Menor: Aranzadi.

- (2015). Tutela de Derechos o Justicia Constitucional. Sobre la objetivación de los recursos de amparo constitucional y europeo. Cizur Menor: Aranzadi.

Anagnostaras, G. (2013). Activation of the Ultra Vires Review: The Slovak Pensions Judgment of the Czech Constitutional Court. German Law Journal (14), 959-973.

Arroyo Giménez, L. (2011). Sobre la primera cuestión prejudicial planteada por el Tribunal Constitucional. Base, contenido y consecuencias. Working Papers on European Law and Regional Integration (8). Disponible en: https://www.ucm.es/data/cont/docs/595-201311-07-sobre\%20la\%20primera\%20cuesti\%C3\%B3n.pdf.

Arzoz Santisteban, X. (2015). La tutela de los derechos fundamentales de la Unión Europea por el Tribunal Constitucional. Madrid: Instituto Nacional de Administración Pública.

Azpitarte Sánchez, M. (2002). El Tribunal Constitucional ante el control del Derecho Comunitario derivado. Madrid: Civitas.

- (2015). Los derechos fundamentales de la Unión en busca de un nuevo equilibrio. Revista Española de Derecho Constitucional (104), 243-268.

Azurmendi, A. (2015). Por un derecho al olvido para los europeos: aportaciones jurisprudenciales de la Sentencia del Tribunal de Justicia Europeo del caso Google Spain y su recepción por la Sentencia de la Audiencia Nacional Española de 29 de diciembre de 2014. Revista de Derecho Político, 92, 273-310. Disponible en: http://dx.doi.org/10.5944/ rdp.92.2015.14428.

Besselink, L. F. M. (2014). The parameters of constitutional conflict after Melloni. European Law Review (4), 531-552.

Biglino Campos, P. (2007). La primacía del Derecho Comunitario, la perspectiva española. Revista General de Derecho Constitucional (3). Disponible en: http://www.iustel.com/v2/ revistas/detalle_revista.asp?id=3.

Clavero, B. (1988). Los derechos y los jueces. Madrid: Civitas.

Crowther, H. (2014). Google vs. Spain: is there a right to be forgotten? Journal of Intellectual Property Law and Practice (9), 892-893. Disponible en: http://dx.doi.org/10.1093/jiplp/jpu148.

Cruz Villalón, P. (1987). La formación del sistema europeo de control de constitucionalidad (1918-1939). Madrid: Centro de Estudios Constitucionales. 
- (2004). La Constitución inédita. Estudios ante la constitucionalización de Europa. Madrid: Trotta.

- y Requejo Pagés, J. L. (2015). La relación entre la cuestión prejudicial y la cuestión de inconstitucionalidad. Revista de Derecho Comunitario Europeo (50), 173-194.

De la Quadra-Salcedo Janini, T. (2015). El papel del Tribunal Constitucional y de los tribunales ordinarios en un contexto de tutela multinivel de los derechos fundamentales. El Cronista del Estado Social y Democrático de Derecho (52), 34-59.

Dicosola, M., Fasone, C. y Spigno, I. (eds.) (2015). The Preliminary Reference to the Court of Justice by the Constitutional Courts. German Law Journal, 16 (6).

Díez García, H. (2014). Igualdad de armas y tutela judicial efectiva en el art. 695.4 LEC, tras el Real Decreto Ley 11/2014 de 5 de septiembre: Crónica de una reforma legislativa anunciada. (De los AATC 70/2014, 71/2014, 111/2014, 112/2014 y 113/2014 a la STJUE de 17 de julio de 2014). Derecho Privado y Constitución (28), 201-262.

Díez Picazo, L.M. (1998). El derecho comunitario en la jurisprudencia constitucional española. Revista Española de Derecho Constitucional (54), 255-272.

Díez-Hochleitner Rodríguez, J. (2013). El derecho a la última palabra: ¿Tribunales Constitucionales o Tribunal de Justicia de la Unión? Working Papers on European Law and Regional Integration, 17. Disponible en: https://www.ucm.es/data/cont/docs/595-2013-1107-el\%20derecho\%20a\%20la\%20\%C3\%BAltima\%20palabra.pdf.

- (2014). Cuestión prejudicial y política judicial. En La Cuestión Prejudicial Europea, IV European Inklings (pp. 164-178). Disponible en: http://www.jeanmonnetcatedra.eu/ european-inklings/.

Épiney, A. (2014). Le Champ d'Application de la Charte des Droits Fundamentaux: l'Arrêt Fransson et ses implications. Cahiers de Droit Européen, 50 (2), 283-303.

Gordillo Pérez, L. I. y Tapia Trueba, A. (2014). Diálogos, monólogos y tertulias. Reflexiones a propósito del diálogo judicial en el caso Melloni. Revista de Derecho Constitucional Europeo (22). Disponible en: http://www.ugr.es/ - redce/.

Groussot, X., Pech, L. y Thor Petursson, G. (2011). The Scope of Application of EU Fundamental Rights on Member States' Action: in Search of Certainty in EU Adjudication. Eric Stein Working Paper (1/2011). Disponbile en: http://www.ericsteinpapers.eu.

Hardy B. (2014). Application dans l'espace de la Directive 95/46/CE: la géographie du droit à l'oubli. Revue Trimestrielle de Droit Européen (4), 879-897.

Huelin Martínez de Velasco, J. (2014). La cuestión prejudicial europea. Facultad/obligación de plantearla. En La Cuestión Prejudicial Europea, IV European Inklings (pp. 44-60). Disponible en: http://www.jeanmonnetcatedra.eu/european-inklings/.

Iglesias Sánchez, S. (2012). The Court and the Charter: the Impact of the Entry into Force of the Lisbon Treaty on the ECJ's approach to Fundamental Rights. Common Market Law Review (49), 1565-1611.

- (2013). Tribunal de Justicia de la Unión Europea [...] Sentencia de 26.2.2013 (Gran Sala)Aklagaren y Hans Akerberg Fransson, Asunto C-617/10. La confirmación del ámbito de aplicación de la Carta y su interrelación con el estándar de protección. Revista de Derecho Comunitario Europeo (46), 1157-1175.

Koutrakos, P. y Shuibhne, N. N. (2014). To Strive, to Seek, to Google, to Forget. European Law Review, 3, 293-294. 
Lohse, E. J. (2015). The German Constitutional Court and Preliminary References. Still a Match not Made in Heaven? 1491-1508. En M. Dicosola, C. Fasone. Y I. Spigno (eds.). The Preliminary Reference to the Court of Justice by the Constitutional Courts. German Law Journal, 16 (6).

López Castillo, A. (1996). Constitución e integración. Madrid: Centro de Estudios Constitucionales.

- (1998). La jurisprudencia iuscomunitaria del Tribunal Constitucional a doce años de la integración española en las Comunidades Europeas. Revista de Estudios Políticos (99), 189-216.

MacCormic, N. (1999). Questioning Sovereignty (Law, State, and Nation in the European Commonwealth). Oxford: Oxford University Press. Disponible en: http://dx.doi. org/10.1093/acprof:oso/9780198268765.001.0001.

Mangas Martín, A. (1991). La Constitución y la Ley ante el Derecho Comunitario (Comentario a la STC 28/1991). Revista de Instituciones Europeas (18), 587-623.

Martín Rodríguez, P. J. (2014). Tribunal Constitucional, Sentencia 26/2014, de 13 de febrero, en el recurso de amparo 6922-2008 promovido por don Stefano Melloni. Revista de Derecho Comunitario Europeo (48), 603-622.

Matia Portilla, J. (2002). La eficacia de la Carta de Niza. En Matia Portilla, J. (dir.). La protección de los derechos fundamentales en la Unión Europea (pp. 123-167). Madrid: Civitas.

Medina Guerrero, M. (2015). Derecho a la vivienda y desahucios: la protección del deudor hipotecario en la jurisprudencia del TJUE. Teoría y Realidad Constitucional (36), 261282.

Pérez Royo, J. y Carrasco Durán, M. (2014). Curso de Derecho Constitucional. Madrid: Marcial Pons.

Pérez Tremps, P. (1985). Tribunal Constitucional y Poder Judicial. Madrid: Centro de Estudios Constitucionales.

- (1994). Constitución española y Comunidad Europea. Madrid: Civitas.

Rallo, A. (2014). El derecho al olvido en Internet, Google vs. España. Madrid: Centro de Estudios Políticos y Constitucionales.

Requejo Pagés, J. L. (2015). Algunas consideraciones sobre la relevancia constitucional del derecho de la UE. En L. Arroyo Jiménez, M. Beladiez Rojo, C. Ortega Carballo y J. M. Rodríguez de Santiago (coords.). El juez del Derecho Administrativo (pp. 493-502). Madrid: Marcial Pons.

Rodríguez Iglesias, G. C. y del Valle Gálvez, A. (1997). El derecho comunitario y las relaciones entre el Tribunal de Justicia de las Comunidades Europeas, el Tribunal Europeo de los Derechos Humanos y los Tribunales Constitucionales nacionales. Revista de Derecho Comunitario Europeo (2), 329-376.

Rubio Llorente, F. (1996). El Constitucionalismo de los Estados Integrados de Europa. Revista Española de Derecho Constitucional (48), 9-33.

Ruiz-Jarabo Colomer, D. (2011). La Justicia de la Unión Europea. Madrid: Civitas.

Saiz Arnaiz, A. (1999). La apertura al Derecho internacional y europeo de los derechos humanos. El art. 10.2 de la Constitución Española. Madrid: Consejo General del Poder Judicial. 
Sánchez Legido, A. (2004). El Tribunal Constitucional y la Garantía de la Aplicación del Derecho Comunitario en España (A propósito de la STC 58/2004). Derecho Privado y Constitución (18), 387-443.

Sarmiento, D. (2012). La aplicación del derecho de la UE por el Tribunal Supremo en tiempos de crisis. Working Papers on European Law and Regional Integration, 13. Disponible en: https://www.ucm.es/data/cont/docs/595-2013-11-07-la\%20aplicacion\%20del\%20derecho\%20de\%20la\%20uni\%C3\%B3n.pdf.

- (2013). Reinforcing the (Domestic) Constitutional Protection of Primacy of EU Law: Tribunal Constitucional. Common Market Law Review, 50 (3), 875-891.

Simón Castellano, P. (2015). El reconocimiento del derecho al olvido digital en España y en la UE. Barcelona: Bosch.

Stone Sweet, A. (2000). Governing with judges, Constitutional Politics in Europe. Oxford: Oxford University Press. Disponible en: http://dx.doi.org/10.1093/0198297718.001.0001.

Torres Pérez, A. (2014). Melloni in Three Acts: From Dialogue to Monologue, European Constitutional Law Review, 10 (2), 308-331. Disponible en: http://dx.doi.org/10.1017/ S1574019614001199.

Ugartemendia Eceizabarrena, J. I. (2013). La tutela judicial de los derechos fundamentales en el ámbito de aplicación nacional del Derecho de la Unión Europea. Recientes acotaciones del Tribunal de Justicia y del Tribunal Constitucional español. Teoría y Realidad Constitucional (32), 391-428.

Vázquez Alonso, V. (2014). Trascendencia constitucional y libertades de expresión e información. En J. M. Morales Arroyo (dir.). Recurso de amparo, derechos fundamentales y trascendencia constitucional (pp. 387-402). Cizur Menor: Aranzadi.

Vidal Prado, C. (2004). El impacto del nuevo derecho europeo en los Tribunales Constitucionales. Madrid: Cólex.

Vírgala Foruria, E. (2002). Tribunal Constitucional, Recurso de Amparo y Unión Europea. En J. Corcuera Atienza (coord.). La protección de los derechos fundamentales en la Unión Europea (pp. 201-236). Madrid: Dykinson.

Walker, N. (2002). The idea of Constitutional Pluralism. The Modern Law Review, 65 (3), 317-359. Disponible en: http://dx.doi.org/10.1111/1468-2230.00383.

Weiler, J. H. H. (1995). Viaje a lo desconocido: pasado y futuro del Tribunal de Justicia en el campo de la integración política. En J. H. H. Weiler. Europa, Fin de siglo (pp. 127-166). Madrid: Centro de Estudios Constitucionales. 